\title{
Exploring the Three-Dimensional Predictors of College Student's Major Fit Based on the SAFE Model
}

\author{
Chang Kyoung Kang ${ }^{1}$, Chang Hoon Seog ${ }^{2}$ \\ ${ }^{1}$ Research Professor, Student Counseling Center, Sunmoon University, Korea, \\ k-changkyoung@daum.net \\ ${ }^{2}$ Professor, Departmen of Liberal Arts, Sunmoon University, Korea, chseog@sunmoon.ac.kr
}

Corresponding author: Chang Hoon Seog

\begin{abstract}
This current study aimed to explore the three-dimensional predictive factors of major fit based on the latest State Authenticity as Fit to Environment (SAFE) model. The SAFE model emphasized psychological fitness including academic aspects, and this psychological fitness was a new approach in that it can predict college students' major fit in college environments. This study analyzed the contents of related literature to predict and derive the major fit factors of college students and to be a qualitative study. This study collected and arranged related factors based on the studies of college students' major fit, and analyzed the main concepts and characteristics focusing on the previous studies on the State Authenticity as Fit to Environment (SAFE) model. The major fit-related factors were applied to the SAFE model, which was the latest college adaptation model, and three-dimensional predictive factors of major fit were derived. The study result showed that the main fit should reflect self-concept fit, goal fit, and social fit, as a major fit predictor based on the State Authenticity as Fit to Environment (SAFE) model, self-concept fit was derived as aptitude, interest, and personality, goal fit was derived as academic motivation, and social fit was derived as teaching-learning relationship. This result suggested that multi-dimensional approach was necessary to predict the major fit of college students. This study is aimed to enhance the understanding of the major fit of college students and provide important implications for effective counseling and career education field.
\end{abstract}

Keywords: College, Students, Major Fit, Predictors, SAFE Model, Three Dimensions

\section{Introduction}

College major is a significant topic in the labor economy and education sector, and many factors affect major choice, including colleagues, course preparation, preferences, labor market conditions, and potential profits. Major selection can be understood as a process that develops over the course of a student's education and can have short-term and long-term consequences that are important for achievement, progress, and sustainability. Therefore, it is significant for students to be interested in their careers and choose the right major for the values, goals, and characteristics they pursue in school[1].

Entering college has a great influence on deciding on a career path or choosing a job depending on whether or not you are confident in your major choice. According to the survey results, it was found that Korean students regret their major choice rather than having confidence in their major choice. A survey of 400 college students in the fourth grade or higher nationwide found that one out of two students regretted their choice of major . In addition, automation will change $50 \%$ of jobs within ten (2020-2030)

Received: July 20, 2021; $1^{\text {st }}$ Review Result: September 08, 2021; $2^{\text {nd }}$ Review Result: October 21, 2021 Accepted: November 30, 2021 
years, and $50 \%$ of Korean college graduates will choose jobs that are not related to their majors. In particular, three out of ten respondents said they want to change their majors, and the smaller the enrollment unit is, the more regretful they are in choosing their major[2].

The choice of major that fits with oneself increases the major satisfaction and plays a positive role in future job and job satisfaction. However, there are cases where students experience inadequateness and are unable to adjust to school life because many students choose the school and major for success, future employment, and information based on advice or guidance from people around them, rather than choosing a major in consideration of their abilities, talents, or interests[3]. In this regard, the importance of individual major fit is emphasized as it is required to understand whether individuals achieve fit and unity for their majors when selecting majors. When individuals perceive the major fit, positive learning outcomes and academic immersion are achieved. Also, since the degree of job, job choice and career design to be performed in the future will be determined, the major fit is an important factor for students in that it can be directly connected to future career paths[4].

However, when the major fit is low, it causes problems such as decrease in satisfaction with the major, job stress and neurosis, and experiences general dissatisfaction in academic, psychological and physical aspects. It can also increase the dropout, which can have a negative impact on students and colleges. As the number of students decreases, the number of students who continue studying decreases, so the college cannot expect the continuous development of the academic field. Colleges may suffer financial difficulties due to the college dropouts and the quality of education. As such, major fit is not only the work of the student but also closely connected with the academic development and quality of education of the college. In particular, as the interest in major fit has increased due to the dropout of students and the expansion of the comprehensive student record system[5], the college utilizes major fit as an evaluation factor for college admission[6]. The evaluation items of colleges based on the major fit are major aptitude, career development activity, interest, passion, goal achievement attitude and support motivation. The reason why major fit is used as an evaluation factor for college admission is that students who enter after grasping major fit can reduce dropout due to the increased possibility of academic achievement and employment through academic immersion and furthermore, it can prevent the consumption of social costs[5].

As such, it is reported that the more detailed the major is considered in the college admissions screening, the better the fit and satisfaction of the college class and the utilization of major fit will be further expanded in college admission as well as in college evaluations. In this regard, the necessity of further study is raised by considering major fit as a new type of fit. There are no studies on various types of individual-environmental fits for academic performance, and there exists a need for further studies on the major fit[7].

The major fit evaluates whether the major has a suitable aptitude for the major in addition to the general academic ability. It includes the major-related academic achievement, the effort process through the interest and activities related to the major, the career aptitude, and the exploration process[8]. More comprehensive and multidimensional approach is required than major satisfaction and major adaptation, which are studied with similar concepts to major fit. Until now, empirical studies have been conducted to identify the factors affecting the major fit by focusing on the psychological, academic, and adaptive aspects of the major[4]. However, the studies on the prediction of major fit are insufficient, so it is necessary to study for the improvement of major fit of Korean college students.

This study is aimed to explore the three-dimensional predictive factors of major fit based on the latest SAFE model. To achieve this purpose, the prior studies of major fit were considered to examine the relevant variables and apply them to the latest State Authenticity as Fit to Environment (SAFE) model to multi-dimensional analysis of predictive factors of major fit. This study is intended to enhance the understanding of college students' major fit and to provide implications for effective counseling and career education for college students by identifying the predictors of major fit. 
Through this study, it was attempted to confirm the importance of college students' major fit and to explore the major fit in an efficient direction for colleges and students. The research question is as follows: What are the predictors of major fit based on the State Authenticity as Fit to Environment (SAFE) model?

\section{Literature Review}

\subsection{Understanding of Major Fit}

The concept of fit has been viewed as an internal consistency among key strategic decisions or the alignment between strategic choices and critical contingencies in either environment (external) or organizational (internal) contexts[9]. This study focuses on the interaction factors of the individual environment and examines the theory of personal environmental fit. The person-environment fit has been a very important concept for human behavior research. Human beings are not independent of the environment and act under certain circumstances or environments. However, there is no consistent concept of individual-environmental fit yet, and the reason is that the fit between individuals and evironments has various meanings such as unity, similarity, harmony, and mutual supplementation[10].

Individual-environmental fit can be distinguished by the perspective of a supplementary fit and a complementary fit. Supplementary fit occurs when an individual has similar characteristics to other individuals in the environment, and complementary fit occurs when the environment complements what the individual's characteristics meet or lack what the environment needs. Complementary fit can then be distinguished in terms of demand-ability fit and needs-supply fit. Demand-ability fit exists when the knowledge, skills, abilities, time, effort, and resources an individual needs can meet the needs of the environment, and needs-supply fit occurs when the environment meets the needs of the individual. Kristof-Brown[11] attempted to incorporate the concepts of reciprocity, complement, demand-ability, and needs-supply. Since human behavior is caused by constant interaction between individuals and the environment, individual-environmental fit occurs when individuals and organizations have similar characteristics, and either individuals or organizations can provide what the other needs. As individuals' perceptions of environmental fit are important to understand their explanations in the environment, it is necessary to understand the fit between the person they experience and the environment. However, this requires an understanding of the interaction between individuals and the environment, in that it involves the understanding that both individuals and the environment are dynamic and always evolving.

Therefore, the individual-environmental fit researchers have been studying how fit between individual-environments can affect individual attitudes and behaviors in various situations (contexts, environments). Individual-environmental fit is a major variable that can predict the attitude and behavior of the organization members because individuals are constantly influenced by various environmental factors such as organization, job, and others, and presupposes that high performance will occur when the characteristics of the organization members and the environment in the organization are appropriate[12].

Since the sub-dimensions that constitute individual-environmental fit can have different effects, the fit between individuals and environments needs to be considered in a wide range of concepts including various aspects of the environment. The categories of environmental fit were divided into individualorganizational fit, individual-job fit, individual-group fit, and individual-person fit. The view that each concept of fit is different was suggested.

Major fit has recently been classified as a new type of fit. Major fit is divided into needs-supply major fit and demand-ability major fit, which is used to better understand the interaction between individuals and the environment. Needs-supply major fit is a type of fit between a person's desire and what the environment supplies, and from a supply-providing point of view, fit occurs when the environment meets 
the individual's desire, hope, and preference. In examining the literature, it is evident that students have various desires for achievement in academic environment, so the fit of needs-supply major can be seen as occurring when students' major needs are suitable for the supply of majors. In terms of demand-ability fit, requirements include task requirements, role expectations and institutional norms and abilities include the aptitude, time, and energy needed to meet these needs. It implies that when an individual can meet environmental needs, the fit occurs, so that students' fit is required in the school environment[7].

In this trend of subdividing fit classification, there is a difference between fit, demand-ability fit and needs-supply fit, but these concepts are ambiguous or overlooked[13]. Therefore, it is necessary to establish the concept of fit clearly and systematically deal with the difference between fits. However, at the same time, it is also required to consider multidimensionally the concept between fits, considering that the fit between individuals and environments is a broad concept that includes various aspects of the environment.

\subsection{Variables Related to Major Fit}

The individual major fit was based on the concept of the individual school fit, and the major selection and the major fit were considered to play a pivotal role in the future as it was most closely related to the job to be performed by the college students[14]. The major fit means the degree of matching between the two when college students link their values and goals with their majors[15] and affects the dropout of students in the college course[5] and play a major role in choosing their own job after graduation as well as college life[16]. Students who choose their major without worrying about aptitude or career can feel less interested with their major, and dissatisfaction can lead to job stress and interfere with motivation. In this case, not only will the major fit be lowered and the school maladjustment will be experienced, but also the number of cases where the transfer to a department or school with a high employment rate will increase as it becomes difficult to get a job related to major[14]. These results show that major fit is closely related to psychology, study, and employment of college students.

The major fit penetrates the domains of personal characteristics, academic, work experience, and life, affecting every aspect of life after entering the college. Specifically, it shows that the major fit is relevant to personal characteristics such as individual aptitude, interest and personality. When the characteristics and abilities of college students are not suitable for the major, it may be difficult to achieve academic achievement during college life[5]. This suggests that individual characteristics such as aptitude, interest and personality are the main factors to increase the major fit, as the characteristics of individuals are also important in the previous studies related to major-interest congruence and college adaptation[17][18].

The major fit provides motivation for learning and is an important factor related on career behavior. The major has a significant impact on employment[5][14], and the higher the major fit, the greater the academic motivation, academic immersion and academic performance. College students feel satisfied with their major by recognizing that it is suitable for their chosen major and has a positive influence on career setting as they are motivated to learn through this positive sentiment.

Furthermore, self-efficacy was reported as a significant variable in major fit and academic relevance[19][20]. Self-efficacy was identified as an influential factor related to success in the curriculum[21]. Students with high self-efficacy tend to continue their tasks persistently in the face of difficulties, with greater immersion, attention, and interest to perform a given task. Among the interests and self-efficacy of majors, self-efficacy was reported to have a greater impact on major adaptation[22], indicating that major fit is related to self-efficacy and can contribute positively to academic immersion and academic continuity.

In addition, the major fit was suggested as a key variable predicting students' adaptation to college 
life. Majors are emphasized as significant factors in adaptation to college life, and major adaptation which is studied as variables similar to major fit and previous studies related to major satisfaction also support this. The consistency between students and majors is an important predictor of the satisfaction of college majors[23].

The major fit is combined with the subjective pleasure of studying the major and the positive thinking about the future career of the individual, which psychologically achieves the unity between the individual and the major, and causes positive results. Therefore, the major fit implies positive attitude toward majors or intention to perform duties in the field related to majors after graduation, and affects the motivation for major selection and major satisfaction[3]. As such, majoring in college has become an important factor in career choice and college life after graduation[5], and it has been involved in the quality of employment and career development and ultimately affects life satisfaction[24]. These results suggest that major fit not only affects college life adaptation but also expands the scope of career development and quality of life after graduation.

\subsection{The State Authenticity as Fit to Environment (SAFE) Model}

Various college adaptation models have been proposed for college students who have lower grades and quit college. Among them, the State Authenticity as Fit to Environment (SAFE) model was introduced in the 29th PURC (Psychology Undergraduate Research Conference) held in UCLA in May 2020. The State Authenticity as Fit to the Environment (SAFE) model provides a way of integrating past models of student performance. This model measures fit along three dimensions: self-concept, social, and goal fit and provides a global perspective of how feeling fit in an environment can affect performance in this environment. Stat Authenticity as Fit to the Environment (SAFE), a conceptual framework for understanding how social identities motivate the situations that people approach or avoid. Three types of person-environment fit is outlined: self-concept fit, goal fit. And social fit. Each type of fit facilitates cognitive fluency, motivational fluency, and social fluency that promote state authenticity approach or avoidance behaviors[25].

In the early studies of college adaptation, academic achievement level has been understood as success of adaptation[26], but considering that the surrounding environment of an individual has an overall impact on adaptation of an individual, it is limited to consider college adaptation simply focusing on academic achievement level[27]. The State Authenticity as Fit to Environment (SAFE) model emphasizes psychological fitness including academic aspects, and this psychological fitness can be a new approach in that it can predict college students' major fit in college environments. In addition, since each fit is interconnected, it can activate the cognitive fluency, motivational fluency, and interpersonal fluency of college students and increase the major fit, so that it can suggest important implications for the major fit based on the psychological fits of college students.

In the literature about the fit between individuals and the environment, the multi-dimensional aspects of environmental factors affecting individuals are presented and the scope is extended. These studies presuppose that individual-environmental fit acts as a major variable that can predict the attitude and behavior of the organization members, and that high performance will occur when the characteristics of the organization members and the environment in the organization are appropriate[12]. It has been found that such an individual environmental fit theory can be applied to college[28], and especially, colleges are one of the subjects that make students fit, and the success of college life depends on how harmoniously and appropriately interacts with these objects, so the most important of the various objects is considered as schools and majors[14]. With reference to these results, this study also applied the major fit based on the State Authenticity as Fit to Environment (SAFE) model, which suggests the fit for the college environment because it is considered important. 
People experience psychological fit in an environment along three dimensions; self-concept fit, goal fit, and social fit. The State Authenticity as Fit to Environment (SAFE) model measures fit on these three dimensions as well[29]. Self-concept fit refers to the extent to which individuals feel they can be their true selves in an environment. Goal fit refers to the extent to which individuals feel like their personal goals match the goals they have to pursue within an environment. Social fit refers to the extent to which individuals feel accepted among or similar to the others in an environment[25][29].

In this model, each fit is conceptually identifiable, but in practice the three dimensions of fit are disproportionately interconnected. Self-concept fit does not include goal fit, but it can also activate the

self in situations involving goal oriented behavior. Each type of fit promotes an internal state of cognitive fluency, motivational fluency, and interpersonal fluency, leading to approach and performance to the goal through true self-awareness. Authenticity is commonly associated with each fit and is also a major factor in the tendency to approach or avoid goal[29].

The State Authenticity as Fit to Environment (SAFE) model is presented in [Fig. 1].

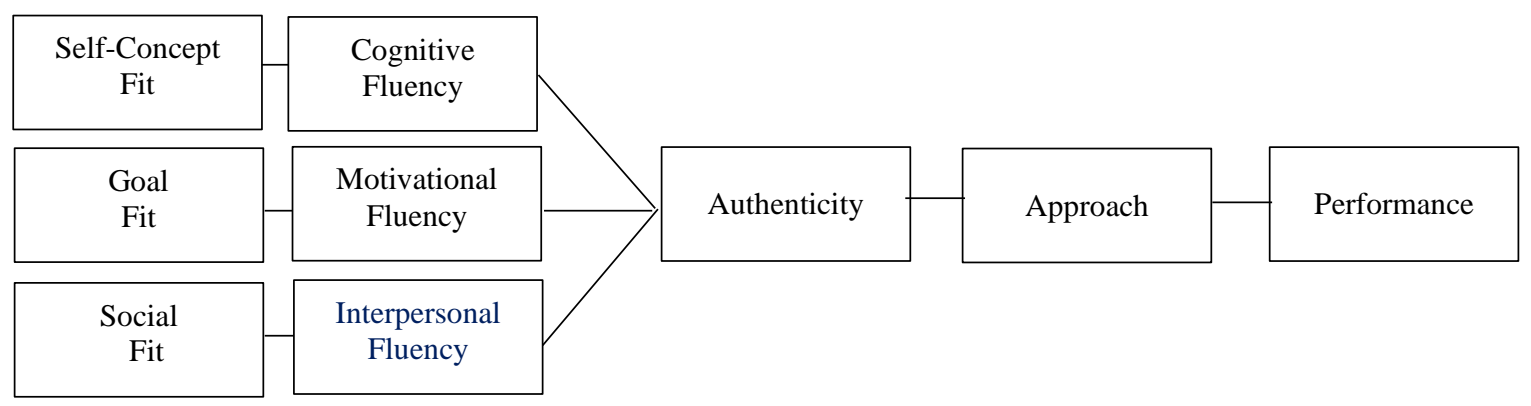

[Fig. 1] The State Authenticity as Fit to Environment Model (Johnson et al., 2020)

This model specifies three ways in which the environment can be suitable for itself. The term fit refers to the characteristics of the environment consistent with its core aspects. At the widest level, a valuable self, i.e. self-concept fit and a more specific institutional structure, is goal fit, and social fit that validates and accepts social signals and interpersonal relationships. Based on this model, this study explores the major fit of college students in a multi-layered manner by applying self-concept fit, goal fit, and social fit [29]. Briefly summarizing each fit above, self-concept fit activates the information about self, personal characteristics, preference, and memory. Goal fit can increase motivation, participation, and interest in situations where the direction of the task is appropriate for the task structure, so if there is a positive motivation, motivation can be strengthened[30]. Finally, social fit is related to interpersonal relationships, and maintaining and monitoring relationships with others is an important factor. Each of these fits promotes cognitive fluency, motivational fluency, interpersonal fluency and leads to authenticity, which can enhance self-understanding, preference, motivation, and interaction ability.

\subsection{Exploring the Three-Dimensional Predictors of Major Fit based on the SAFE Model}

The first type of fit outlined in the State Authenticity as Fit to Environment (SAFE) model is selfconcept fit. Self-concept fit promotes cognitive fluency[29], and individual aptitude, interest, and personality become the function of major fit. An examination of the literature reveals the self-concept of the individual's characteristics, aptitude, interest, and personality are highly relevant to the major fit. Therefore, the major fit can be enhanced considering the aptitude, interest, and personality of the individual. This is because the said individual characteristics are consistently satisfied and are essential factors in selecting the educational environment with the greatest possibility of success[31]. 
The second type of fit outlined in the State Authenticity as Fit to Environment (SAFE) model is goal fit. The major fit means the extent of fit that the college students' own values and goals are linked to their majors[14][15], and can be expressed as the goal clarity that establishes specific plans and promotes the actions that follow them. Goal fit is related to motivational fluency and promotes academic motivation and academic achievement to increase major fit. In the previous literature discussed about goal fit, the motivational effect of goal fit is that one feels that one's behavior is self-determined and becomes a common element in itself[29].

The final type of fit outlined in the State Authenticity as Fit to Environment (SAFE) model is social fit. The key element of social fit is interpersonal fluency, which occurs in situations where individuals, intergroup interactions, or relationships or identities are verified[29]. As an academic community, the formation of a teaching-student relationship plays an important role in students' academic commitment, motivation, and academic achievement. Especially, the role of the professor was found to be important because the major fit has a positive effect on academic achievement through academic commitment[28].

However, not only the interaction with the professor but also the college students are greatly influenced by the quality and quantity of peer interaction[32]. Friendship failure causes students to experience isolation and makes it difficult to achieve academic achievement, while friendship formation prevents dropout and has a positive relationship with adaptation to major. Peer relationships are related to adaptation to learning and attachment to colleges, which is supported in a previous literature[33]. That is, it is inferred that the professor-student relationship could increase the major fit because the relationship with friends has an important influence on academic achievement, major adaptation and major persistence.

\section{Methodology}

\subsection{Data Collection Procedure}

The purpose of this study is to investigate the predictors of major fit of college students based on the State Authenticity as Fit to Environment (SAFE) model. To this end, the previous studies on the major fit of college students were examined and the related variables were presented as shown in [Table 1].

[Table 1] Related Variables of Major fit of Colleg Students

\begin{tabular}{c|c}
\hline Authors & Variables \\
\hline Kim [28] & Learning motivation \\
\hline Kim [17] & Major satisfaction, Major adujstment \\
\hline Min [4] & Basic psychological needs, adjustment to college life \\
\hline Park [6] & Self-determination, adjustment to college life \\
\hline Seo [32] & Personality, self-efficacy \\
\hline Xue Jia [19] & Self-efficacy, learning commitment \\
\hline Yun [3] & Major selection motivation \\
\hline Lim [6] & Aptitude, interest \\
\hline Naghmeh et al [7] & Academic achievement \\
\hline Zhou \& Xuan [24] & Self-evaluation, Life satisfaction \\
\hline
\end{tabular}

The concept, components and characteristics of the State Authenticity as Fit to Environment (SAFE) 
model were examined and the factors related to major fit were identified. The major fit variables summarized in the previous studies were applied to the components of the State Authenticity as Fit to Environment (SAFE) model to derive factors related to major fit. For this study, literature analysis was used to conduct the research procedure, and the factors related to the major fit of college students were collected, analyzed and discussed, focusing on the literature related to the major fit and State Authenticity as Fit to Environment (SAFE) model for college students. Through this research procedure, by driving the major fit factors of college students based on the State Authenticity as Fit to Environment (SAFE) model, educational implications can be used in the college education field.

The steps above are presented in [Fig. 2].

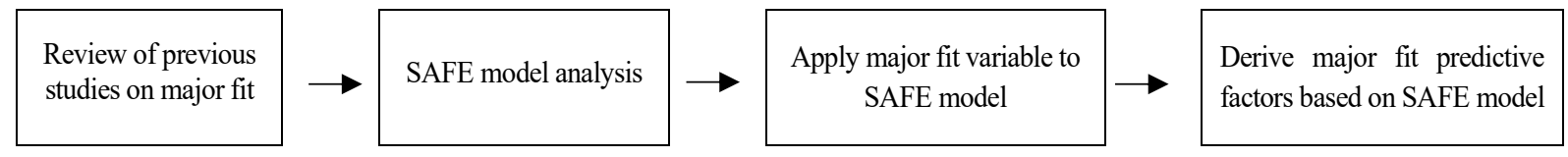

[Fig. 2] Research Process

\subsection{Reaserch Design}

The purpose of this study is to predict factors related to major fit of college students as qualitative research. For the study, The research design is composed of three steps as follows. The first step is to set up research questions, the second step is to search and select previous studies related to research questions, and the next step is to analyze data and collect results on selected research.

\subsection{Data Analysis}

The data analysis included previous studies that focused on the major fit of college students in the analysis subject; objectivity, strictness, and accuracy are required in the selection process of the analysis subject literature[34]. To minimize the omission and to reflect the research subjects to be analyzed, keywords were synthesized based on 'college students' and 'major fit', and data were collected through cross-search by putting them into search services such as KCI, RISS (Research Information Service System), DBpia, and KISS. The collected studies were used to analyze the factors related to the major fit of college students and to predict the factors related to the major fit. The content analysis of the research topic was focused on the research subject, the main words, and the research abstract. After reading the entire paper, the factors related to the fit of college students were included in the core area. After analyzing the concept and characteristics of the State Authenticity as Fit to Environment (SAFE) model, each factor of major fit was applied to the SAFE model to derive the SAFE model-based major fit prediction factors.

\subsection{Reaserch Method Limitations}

The purpose of this study is to derive the factors of major fit based on the State Authenticity as Fit to Environment (SAFE) model, which is useful for understanding the difference in interpretation or meaning of major fit through qualitative research. However, qualitative research may lack objectivity in research procedures and research methods, and it is necessary to provide objective grounds for qualitative research that is easy to be subjective. Therefore, the study has limitations that can not be applied in other situations. 


\section{Result}

Based on the latest State Authenticity as Fit to Environment (SAFE) model, this study explored the three-dimensional predictors of major fit in multiple dimensions. The three-dimensional fit of this model was suggested to be connected to the performance of majors by strengthening the motivation for access to majors when they recognize true self through self-concept fit (cognitive fluency), goal fit (motivational fluency), and social fit (interpersonal fluency). As a result of applying the variables related to major fit to the State Authenticity as Fit to Environment (SAFE) model based on the previous studies, self-concept fit as a predictor of major fit was derived as interest, aptitude, and personality, goal fit as academic motivation, and social fit as professor-peer relationship. The results of this study are presented in [Fig. 3].

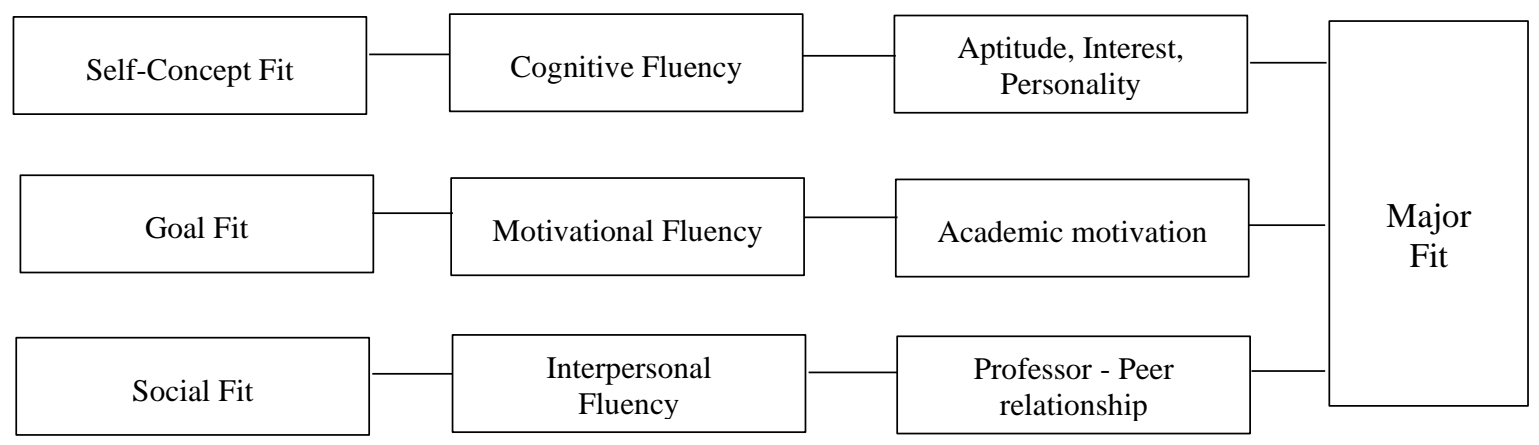

[Fig. 3] Exploring the Three-Dimensional Predictors of Major Fit based on the State Authenticity as Fit to Environment (SAFE) model

\section{Discussion}

This research results showed that self-concept fit was derived as aptitude, interest, and personality, goal fit was derived as academic motivation, and social fit was derived as professor-peer relationship as State Authenticity as Fit to Environment (SAFE) model -based major fit predictors. The first type of the three dimensions of fit is self-concept fit, and it is suggested that individual ability, interest, and personality are functioning as a match or fit with the major field in relation to the growth of students[31]. As such, majors are related to individual characteristics such as individual personality, interest, and aptitude, among which aptitude and interest were emphasized as the most representative factors as the elements of self-understanding for career choice[8]. This reflects that it is important to understand one's aptitude, interest, and personality in majors, and that the more self-conceptualization is made based on understanding of oneself, the more cognitive fluency such as academic achievement and grades is activated, and the more appropriateness of majors can be increased. Therefore, in order to develop the major fit, it is necessary to understand the characteristics and personality of oneself and to promote the development of cognitive fluency by embodying self-concept.

It is noteworthy that even if the individual interest and major consensus are high, the level of major adaptation is low[18]. Thus, given that the level of aptitude and interest in a major is high, it may be unreasonable to affirm the major fit similar to major adaptation will also be high. The three-dimensional fit structure has a smooth approach-performance to the major through the conceptualization of true self, where each factor corresponding to fit is mutually influenced and predicted the major fit.

The second type of fit outlined in the State Authenticity as Fit to Environment (SAFE) model is goal fit. Goal fit is relevant to the increase of major fit when the values and goals that they pursue are linked 
to their majors and have unity. The higher the fit between individual goals and values, and the more situational motivations are given in any environment, the more work engagement, motivation and selfdetermination can be promoted[29]. According to goal setting theory, clearly set and recognized goals are motivated by self-regulation effect, as well as synchronizing individuals to develop effective learning strategies and directly controlling individual activities[6]. Considering that the students who set well goals are well adapted to school and the dropout rate falls, it can be said that setting goals for major and job choice are very important for college students[33]. The goal is to induce motivation for study, and the motivation for study is relevant to the learning of college students. In addition, the higher the achievement motivation level, the higher the learning immersion and learning strategy[35].

The goal is to influence cognitive participation through various motivational processes and consequently, it causes differences in learning attitude and performance[36]. Therefore, in order to improve the major fit, it is necessary to consider whether their values and goals are appropriate for the direction and vision of the major, and to strengthen the motivation of the students to the major and circulate them into academic achievement. In other words, the academic motivation of goal fit affects the attitude and performance of the major, which is an important factor in predicting the major fit.

The last type of fit outlined in the State Authenticity as Fit to Environment (SAFE) model is social fit. Social relationships within the college not only provide students with growth experiences but also discover their goals and talents[33]. When college students perceive the major fit high, they have high ability to interact with others through social relationship formation and can form and maintain a good interpersonal relationship[15]. Regarding major fit, the relationship between professors and peers is particularly emphasized in the college. Professor-peer relationships have been reported to be related to social, emotional, and physical adaptation as well as to academic performance, academic continuation, academic adaptation, academic achievement, and major satisfaction[33]. These results reflect the need to expand the positive interaction experience of professor-peer relationships in order to predict the major fit and to increase the performance-satisfaction related to the major. For this purpose, it is necessary to encourage participation in group counseling for improving interpersonal skills and major adaptation programs, and to provide opportunities for forming relationships between professors and peers through joint project education and encouraging participation in learning communities. This is because developing fluency in professor-peer relationships while experiencing the fit through various social structures and interactions related to majors is an important factor in the major fit.

\section{Conclusions}

This study analyzed the three-dimensional fit based on the State Authenticity as Fit to Environment (SAFE) model and applied the major fit to the SAFE model in a multi-dimensional manner. The results of this study show that it is necessary to establish self-concept and improve understanding of oneself in order to improve the major fit. This suggests that the self concept such as personality, attitude, and interest of individuals can affect the major fit. Also, if they recognize that their chosen major is suitable, they have motivation to learn through satisfaction with their major and positive emotion and experience. In this regard, major fit was related to establishing their own goals and developing academic motivation factors through goal fit. In addition, the individual-major fit depends on the school itself, major, professor, senior and senior students, and the success of college life in harmony with them and appropriately interacting with them. Therefore, to improve the major fit, it is important to set goals based on the understanding of oneself, to raise academic motivation, establish social relationships, and actively form the friendship with professors.

This study examined the predictors of major fit by applying the latest college adaptation model in the situation where research is limited in the field of domestic career education compared to its importance. Since the major fit is used in a mixture of the meanings of major interest congruence, major satisfaction, 
and major adaptation, it is essential to establish the concept of major fit and a theoretical foundation to overcome these limitations. Therefore, this study will contribute to the promotion of academic interest in related fields by suggesting useful grounds for establishing conceptual knowledge and theoretical system of major fit.

Additionally, the findings of this study are useful as basic data for developing program and counseling intervention strategies to improve the ability of major fit in career education and counseling. Although there are programs for college adaptation and career competency development in career education and career counseling in colleges, systematic education and program operation to improve the major fit are insufficient. In the trend of cross-regionalization and major diversification, predicting the major fit can help prevent major maladjustment by reviewing the major fit in advance, so it is expected that its usefulness will be great in career counseling and education. The findings of this study will contribute to the preparation of concrete measures to improve the major fit of college students. High fit of majors helps improve major skills and can enhance professionalism in entering major fields in the future, which has implications to promote students' career development ability.

With the introduction of the Liberal Arts Department, the importance of fostering talented people majoring in various disciplines is emphasized, and the predictor of major fit can provide implications for strategies and policies for cultivating talented people in colleges. The Liberal Arts Development has advantages because it strengthens students' choice and provides various opportunities, but many students feel heterogeneity in their majors or do not have a sense of belonging to the department.Therefore, the predictors of the major fit will be able to raise the purpose of Liberal Arts Development and to suggest effective directions for the development of the majors of the school.

This study has several suggestions and recommendations for future follow-up studies. First, this study was analyzed based on the latest State Authenticity as Fit to Environment (SAFE) model, so there was a limit to searching for sufficient data because there were not enough previous studies on the model. It is necessary to accumulate related to the research and check the effectiveness of the State Authenticity as Fit to Environment (SAFE) model in Korea. Second, this study explored that people experience psychological fit in an environment along three dimensions; self-concept fit, goal fit, and social fit,. This study suggests that there are limitations in comprehensive understanding of major fit. Therefore, in the further studies, in addition to the three dimensions, it is required to search further considering the multidimensional aspect that can affect the major of college students. Third, the prediction factors of major fit derived from this study need to be supplemented in terms of validity. For this, objective verification process should be conducted through statistical analysis of major fit predictors derived from this study. Fourth, it is necessary to investigate the predictors of major fit by major. Since the factors of major fit can be varied and subdivided according to the characteristics of each major, it may be effective in practical aspects to search for predicting major fit factors reflecting the characteristics of each major. Fifth, it is required to develop scale related to major fit. Providing information on the level of major fit through the development of the major fit scale can be useful for career counseling and career strategy establishment to increase major fit in the educational field.

\section{References}

[1] C. Astome-Figari, J. D. Speer, Are changes of major changes? The roles of grades, gender, and preferences in college major switching, Economics of Education Review, (2019), Vol.70, pp.75-93, DOI: 10.1016/j.econedurev.2019.03.005

[2] J. S. Han, Unmatch and improvement direction in labor market for college graduates from the perspective of major selection, KDI FOCUS, (2020)

[3] K. H. Yoon, Impacts of major selection motivation on person-university fit, person-major fit, major satisfaction and job 
seeking efficacy in food \& culinary arts students : focused on mentoring, Sejong University, Doctoral Dissertation, (2015) pp.1-139.

[4] J. W. Min, Relation between person-major fit and adjustment to college life: the moderating effect of basic psychological needs in class, Sookmyung Woman University, Master Thesis, (2020), pp.1-83.

[5] S. H. Jeon, S. H. Kim, Y. S. Ko, S. H. Jung, Development of Program to Facilitate High School Students' Search for Potential College Majors and Future Career as Career Education: Focusing on Connection between High School Home Economics and College of Human Ecology Majors, Journal of Home Economics Education Research, (2015), Vol.27, No.2, pp.53-75, UCI: G704-000502.2015.27.2.002

[6] J. A. Park, The effect of self-determination and personal-major fit of college students on adjustment to college: analysis of the admission type and major of the department, Ewha Woman University, Master Thesis, (2019), pp.1-101.

[7] V. Naghmeh, R. Samsilan, A. Maria, O. Zoharah, Relationship between Need Supply Major Fit and Demand Ability Major Fit with Academic Achievement, Journal of Education and Human Development, (2016), Vol.5, No.2, pp.196206, DOI: 10.15640/jehd.v5n2a23

[8] E. Im, Developing a instrument for evaluating fitness of college major in the field of science and technology, The Journal of Career Education Research, (2006), Vol.19, No.3, pp.1-21, UCI: G704-001285.2006.19.3.004

[9] P. C. Ensign, The concept of fit in organizaional research, International Journal of Organization Theory and Behavior, (2001), 4(3), pp.287-306, DOI: 10.1081/OTB-100105406

[10] Y. S. Kang, Differential Effects of Person-Environment Fit on Job performance and Mediating Effect of Perceived Work Value, Journal of Human Resource Management Research, (2012), Vol.19, No.4, pp.75-98, UCI: G704-001783. 2012.19.4.011

[11] A. L. Kristof, Person-organization fit: An integrativereview of its conceptualizations, measurement, and implications, Personnel Psychology, (1996), Vol.49, No.1, pp.1-49, DOI: https://doi.org/10.1111/j.1744-6570.1996.tb01790.x

[12] H. J. Kim, S. J. Kim, Effects of Person-environment Fit on the Job Performance of Public Officials, Journal of the Korea Contents Society, (2020), Vol. 20, No. 8, pp.559-571, DOI: 10.5392/JKCA.2020.20.08.559

[13] J. Y. Sung, W. W. Park, S. H. Yoon, The Effect of Person-Environment (Organization, Supervisor, Coworker) Fit, on Organizational Citizenship Behavior and Performance, and the Mediating Effect of Justice, Korean Journal of Management, (2008), Vol.16, No 2, pp.1-62, UCI: G704-000359.2008.16.2.003

[14] Y. H. Cho, J. C. Jung, M. Myung, The Effects Person-University Fit(PUF), Person-Major Fit(PMF) on Employability and Educational Achievement: The Role of Learning Flow as A Mediator, Mentoring as A Moderator, Korean Journal of Business Administration, (2013), Vol.26, No.3, pp.749-780, UCI: G704-000789.2013.26.3.012

[15] D. J. Choi, M. S Lee, The Effect of Person-Major Fit on Social Self-efficacy of University Students Majoring in Food \& Culinary Arts: Focusing on Mediation Effect of Major Satisfaction, Journal of Foodservice Management, (2019), Vol.22, No.6, pp. 69-91.

[16] J. Y. Jang, H. C. Shin, J. Y. Lee, The Effect of Commitment toward College Major on the Quality of Employment among College Graduates, Korean Journal of Industrial and Organizational Psychology, (2007), Vol.20, No.4, pp.415435, DOI: $10.24230 / \mathrm{ksiop} .20 .4 .200711 .415$

[17] Y. H. Kim, J. H. Jung, K. H. Kim, Influence of Choice and Satisfaction of Career on School Adjustment among College Students Majoring in Health Care, Journal of the Korea Contents Society, (2014), Vol.14, No.12, pp.538-544, DOI: 10.5392/JKCA.2014.14.12.538

[18] M. H. Yang, M. J. Park, H. J. Kim, The Effects of Congruence, Score Elevation \& Types of Interest on College Students' Career Maturity and Satisfaction with Major, The Journal of Vocational Education Research, (2010), Vol.29, No.2, pp.137-156, UCI: G704-000975.2010.29.2.001

[19] Xue Jia, The Effects of Person-Organization Fit and Person-Major Fit on the Learning Flow and Learning Interest among Chinese Students in Korea - Focusing on the Mediating Effects of Self-efficacy-, Honam University, Master Thesis, (2020), pp.1-171.

[20] Y. S. Seo, A Study on the Correlation of Personality traits and Emotional Intelligence to Major Satisfaction in Computer 
Science, Incheon National University, Master Thesis, (2020), pp.1-61.

[21] M. Aryee, College students' persistence and degree completion in science, technology, engineering, and mathematics (STEM): The role of non-cognitive attributes of self-efficacy, outcome expectations, and interest, Seton Hall University, Doctoral Dissertation, (2017), pp.1-153.

[22] H. Y. Kang, The relationship among Interest- Major Congruence, self-efficacy and Major Adjustment in Science and Engineering for College Students, Korean Journal of Counseling, (2011), Vol.12, No.1, pp.115-127, DOI: $10.15703 / \mathrm{kjc} .12 .1 .201103 .115$

[23] A. Milsom, J. Coughlin, Examining Person-Environment Fit and Academic Major Satisfaction, Journal of College Counseling, (2017), Vol.20, No.3, pp.250-262, DOI: https://doi.org/10.1002/jocc.12073

[24] J. Zhou. J, Xuan, Core self-evaluation and life satisfaction: The person-environment fit perspective, Personality and Individual Differences, (2015), Vol.75, pp.68-73, DOI: http://dx.doi.org/10.1016/j.paid.2014.11.013

[25] J. Johnson, A. Munasinghe, D. Mackie, Scale Validation: Student Fit in a college Environment(S'FICE), University of California, (2020)

[26] H. Gerdes, B. Mallinckrodt, Emotional, Social, and academic adjustment of college students: A longitudinal study of retention, Journal of Counseling and Development, (1994), Vol.72, No.3, pp.281-288, DOI: 10.1002/j.15566676.1994.tb00935.x

[27] E. A. Kim, Developing a Prediction Model regarding Adjustment of Nursing Students to College Life, Chonnam National University, Doctoral Dissertation, (2011), pp.1-122.

[28] B. Y. Kim, Effects of a Person-Environment Fit on Faculty Trust, Journal of Tourism Sciences, (2016), Vol.40, No.5, pp.67-85, DOI: 10.17086/JTS.2016.40.5.67.85

[29] T. Schmader, C. Sedikides, State Authenticity as Fit to Environment: The Implications of Social Identity for Fit, Authenticity and Self-Segregation, Personality and Social Psychology Review, (2017), Vol.22, No.3, pp.228-259, DOI: $10.1177 / 1088868317734080$

[30] M. M. Vainio, D. Daukantaite, Grit and different aspects of well-being: Direct and indirect relationships via sense of coherence and authenticity, Journal of Happiness Studies, (2016), Vol.17, pp.2119-2147, DOI: 10.1007/s10902-0159688-

[31] K. A. Feldman, C. A. Ethington, J. C. Smart, A Further Investigation of Major Field and Person-Environment Fit: Sociological Versus Psychological Interpretations of Holland's Theory, The Journal of Higher Education, (2001), Vol.72, No.6, pp.670-698, DOI: https://doi.org/10.2307/2672899

[32] C.-S. Davis, A. B. Ginorio, C. S. Hollenshead, B. B. Lazarus, P. M. Rayman, The equity equation: Fostering the advancement of women in the sciences, mathematics, and engineering, Jossey-Bass Publishers, (1996)

[33] H. E. Kim, K. W. Kim, Influence of friendship to academic persistence and drop out and mediation effect of school adaptation, Journal of Fashion Business, (2011), Vol.15, No.4, pp.87-109, UCI : G704-001042.2011.15.4.002

[34] S.W. Park, A Study on the Research Trends of In-Service Teacher Education in Korea: Implications and Tasks, The Journal of Korean Teacher Education, (2014), Vol.31, No.2, pp.227-254, DOI: 10.24211/tjkte.2014.31.2.227

[35] H.W. Bang, G. P. Cho, The Differences of Learning Flow, Academic Emotional Regulation, and Learning Strategies according to Achievement Motivation Level of University Students, Journal of Learner-Centered Curriculum and Instruction, (2019), Vol.19, No.10, pp.331-350, DOI: 10.22251/jlcci.2019.19.10.331

[36] J. H. Ahn, The Relationship between Achievement Goal Orientation and Intrinsic Motivation of University Dance Majors, Kookmin University, Master Thesis, (2013), pp.1-81. 